\title{
E-Learning Technology in Pre-Service Teachers Training - Lessons for Ethiopia
}

\section{Ziyn Engdasew Woldab (Ph.D)}

\author{
Ass. professor, and Dean of School of Educational Sciences \\ Adama Science and Technology University \\ Email:engdasewziyn@yahoo.com
}

\section{Doi:10.5901/jesr.2014.v4n1p159}

\begin{abstract}
Dynamic changes in technology can have a profound effect on teacher's education. With technology evolving at such a rapid rate, it is imperative that teachers training institutions equip teacher trainees with technological skills that are essential for coping in the wider learning community. These skills are most effectively gained by learning with technology, rather than about technology. Despite increasing number of technologies and level of educational technology provided by teacher education programs, effective and high-level integration of technology into learning and teaching processes is not still as expected. The purpose of this review was to ascertain how pre-service teachers training institutions were using an e-learning technology in global context and what factors affected successful implementation of e-learning and how they remedy the barriers, so as to gain lessons for Ethiopia teachers training institutions. More specifically, this review sought to examine the basic features, advantages and disadvantages of e-learning, barriers and its remedy toward the effective utilization of the e-learning technopedagogy for quality teachers education. The review results indicated that successful implementation of the e-learning technology in pre-service teachers training was dependent on the four key factors of ICT infrastructure, ICT leadership, support and training initiatives and the teachers' and trainees ICT capacity. These four factors are not hierarchical in nature, but are all equally important.
\end{abstract}

Keywords: Educational technology, E-learning, pre-service teachers training, Techno-pedagogy

\section{Introduction}

Teacher's education is an area of great significance in any country. A sound programme of teacher's education and effective teachers training institutions are essential for the qualitative improvement of overall education system of a nation. It is a truism that without improving the quality of teacher's education, the quality of schools education cannot be improved (Sharma, 2003). Quality of school education is the direct consequence and outcome of the quality of teachers and teacher's education system. Quality assurance in teacher's education is a key to quality assurance in education itself (Mukhopadhaya, 2002).

The quality of teacher education is dependent partly on entry qualification of students, teachers training, infrastructural and techno- pedagogical facilities available in the teachers training institutions. Among others, the role of techno-pedagogical facilities in teacher's education sector is increasing at a phenomenal rate and revolutionalized traditional forms of teaching-learning processes (Mukhopadhaya, 2002).

Now a days, educational technology as part and parcel of techno-pedagogic innovations, is becoming a fast growing science, committed to converting raw-hand teachers in to really effective and efficient ones by equipping them with practical teaching skills and qualities of creative teaching. It has undergone a revolution in respect of new methods employed in teaching at different levels (Sharma, 2003).

In view of the advancing educational technology which has made teacher education a comprehensive and technology oriented, there is practical need for better teacher education in Ethiopian education system to make the present day teacher to perform his duties most effective for the good of the educants in particular and society in general. Quite obviously, the first comprehensive purpose in the use of educational technology would be to improve and extend learning or understanding, facilitate and increasing motivation for learning and realism of experiences (Sharma, 2003).

One of the important educational technology/ techno-pedagogical innovations is e-learning, which may be described as the application of internet or intranet computers to assist teaching and learning. E-learning is being implemented today in various forms and through a variety of tools- e-mails, blogs, wikis, animations and e-lessons. The rise of this new educational technology is also partly due to the limited capacity in transmitting education in traditional ways (i.e face-to-face classroom sections), which fail to adequately meet the increasing demands of quality education 
(Sing, 2000).

E-learning becomes beneficial to all type of learner in general trainees of teacher's education in particular. It is affordable, saves time, and produces measurable results. It is also more cost effective than traditional learning because less time and money is spent. Flexibility is a major benefit of e-learning. It has the advantage of taking class anytime anywhere. Education is available when and where it is needed. It accommodates different types of learning styles. Trainees in teacher education have the advantage of learning at their own pace (Sing, 2008).

The Ministry of Education in Ethiopia is currently implementing the General Education Quality Improvement Program (GEQIP) in order to improve the quality of education in the country. Teacher Development Program (TDP) is one of the pillars of GEQIP, which aims at improving the quality of the teaching force. Improving the Quality of Primary Education Program (IQPEP) is also a program that focuses on improving the quality of education, with two of its components, i.e. pre-service and in-service teacher education components. The pre-service component focuses mainly on establishing new Centers of Excellence and Resource Centers and strengthening the existing ones, and enhancing the use of e-learning technology in the form of simple e-lessons.

It was learnt that although training has been given to some of the teacher educators on e-learning technology utilization and implementation in general and on e-lessons development, they are not currently used in the teaching learning process in almost all of the teacher training institutions due to poor capacity to implement e-lessons, lacks/ shortage of computers, LCDs, laptops and software, absence of training opportunities for instructors, instructors' lack of basic skills in computer operation, shortage of budget and extremely limited internet service(AED,2010).

Based on these preliminary findings, in this paper an attempt was made to review literature and draw lesson on the proper implementations strategies and utilization of E-learning technology for the improvement of the quality of Teachers trainings in Ethiopian Institutions of Teachers' Education.

\section{E-Learning Technology - Overview}

E-learning refers to a variety of learning experiences that use technology to support and enhance learning and teaching. It is a flexible term used to describe as a means of teaching through technology (Comerchero, 2006). It is commonly referred to the intentional use of information and communications technology in teaching and learning. A number of other terms are also used to describe this mode of teaching and learning. They include online learning, virtual learning, distributed learning, network and web based learning. It is used to portray any type of learning environment that is computer enhanced learning experience, which takes place away from the actual classroom (Naidu, 2006).

It is a new form of techno-pedagogical approach, in which educationalists demonstrate "technological fairness" and explore new ways of using the technology autonomously for students learning. E-learning affords opportunities to design learning environments that are authentic, situated in the learning context, and also problem-based in order to provide students with "learning by doing" experiences (Naidu, 2006).

E-learning is a means of education that incorporates self-motivation, communication, efficiency, and technology. Because there is limited social interaction, students must keep themselves motivated. The isolation intrinsic to e-learning requires students to communicate with each other and the instructor frequently to accomplish their assigned tasks(Comerchero, 2006).Fundamentally, they all refer to educational processes that utilize information and communications technology to mediate asynchronous as well as synchronous learning and teaching activities (Catherall, 2005).

According to Naidu (2006), E-learning has in general four major modalities which provide diverse opportunities for users. Some of the modalities are:

Individualized self-paced e-learning online: refers to situations where an individual learner is accessing learning resources such as a database or e-courses content or lessons online via an Intranet or the Internet. A typical example of this is a learner studying alone or conducting some research on the Internet or a local network.

Group-based e-learning synchronously: refers to situations where groups of learners are working together in real time via an Intranet or the Internet. It may include text-based conferencing, and one or two-way audio and videoconferencing. Examples of this include learners engaged in a real-time chat or an audio-videoconference.

Group-based e-learning asynchronously: refers to situations where groups of learners are working over an Intranet or the Internet where exchanges among participants occur with a time delay (i.e, not in real time). Typical examples of this kind of activity include on-line discussions via electronic mailing lists and text-based conferencing with in learning managements systems.

Individualized self-paced e-learning offline: refers to situations where an individual learner is using learning 
resources such as a data base or a computer-assisted learning package offline (i.e., while not connected to an Intranet or the Internet). An example of this is learners learn alone already designed e-lessons or e-courses through a hard drive, like a CD or DVD. In such modality e-lessons or courses provides an opportunity and encourages self directed study skills for learners. This lets student's work at their own pace and at their spare time. Any time e-lessons are available, making it attractive alternative to traditional trends and modalities in training in a classrooms. It enables participants to facilitate lifelong learning by acquiring information, improving skills and developing individual abilities, at a pace set by each student ( Naidu, 2006).

\section{Basic Features of E- Learning Technology}

A basic feature of information and communications technology in general, is its ability to enable flexible access to information and resources. Flexible access refers to access and use of information and resources at a time, place and pace that is suitable and convenient to individual learners rather than the teacher and/or the educational organization (Willems, 2005).

It has been able to do this with the help of information and communications technologies which afford learners access to up to-date information as and when they need them, and also the opportunity to discuss this information with their peers and teachers at their convenience. This is becoming increasingly affordable and palatable with a wide range of software applications and computer conferencing technologies for collaborative inquiry among students. These applications enable learners and teachers to engage in synchronous as well as asynchronous interaction across space, time, and pace (Naidu,2006).

Information and communications technology also enables to capture and store information of various types including print, audio, and video. Networked information and communications technologies enable access to this content in a manner that is not possible within the spatial and temporal constraints of conventional educational settings such as the classroom or the print mode (Dede, 2000). In the context of this distributed setting, users have access to a wide variety of educational resources in a format that is amenable to individual approaches to learning (Spiro, Feltovich, Jacobson \& Coulson,1991), and accessible at a time, place and pace that is convenient to them (Pea, 1994). Typically, these educational resources could include hyper-linked material, incorporating text, pictures, graphics, animation, multimedia elements such as videos and simulations and also links to electronic databases, search engines, and online libraries.

E-learning, like any organized educational activity is a very complex undertaking. Many organizations seeking to engage in e-learning activities quite often overlook the fact that its successful deployment requires the same level of diligence and rigor in its planning, management and implementation that is necessary in setting up conventional education systems. In fact, e-learning has added elements such as the technology infrastructure that require attention far beyond that is necessary in conventional educational settings (Naidu, 2006).

Furthermore, e-learning is neither a cheap nor an easy educational option. It does not offer a quick fix for problems associated with dwindling enrollments, distance education, or poor teaching and learning. Lack of careful planning and implementation of e-learning can actually lead to decreasing standards and morale, poor performance in learning and teaching, and wasted resources and loss of revenue. Any efforts to embark on e-learning must be preceded by very careful planning. This would necessarily comprise, strategic and operational planning that are consistent with the values, mission and goals of an organization (lbid).

Educational organizations that have a history of employing alternative approaches to learning and teaching such as distance education will have many of the prerequisites and dispositions for e-learning already in place which they can easily capitalize and build upon. However, conventional campus-based educational organizations that have traditionally relied on residential face-to-face classroom-based learning and teaching activity would need to reconsider their values, mission and goals of educational provision in order to adequately accommodate the adoption of e-learning activities (Giunti, 2009). A critical component of this orienting or reorienting for the successful adoption of e-learning is institutional sponsorship. For e-learning to succeed in any setting, there has to be complete support for the initiative from the highest levels. This is important not only because it will have implications for funding allocation for any such new initiative, but also because of its implications for the mindset of the rest of the organization. Staff needs to buy into the initiative and be committed to its success (Hawkridge, 1979).

Like any other organized educational activity, e-learning, is a team effort, as a number of people and a range of expertise need to be brought together to make e-learning workable. In conventional educational systems, course design and development is the sole responsibility of the subject matter expert who is also the teacher. E-learning will require the 
delivery of that subject matter content in alternative forms such as online or on a CD-ROM. Some teachers are able to produce their content themselves. However, this might not be the best use of their time and expertise in most educational settings (Naidu, 2000).

Without this kind of ground swell of support and commitment from its foot soldiers; any such new initiative is doomed for failure in any organization. These are the preconditions for the successful deployment of e-learning, and they have to be in place as part of the preparation for its deployment in any organization. Without adequate attention to these preconditions, e-learning is unlikely to achieve its full potential in any organization; no matter how robust and reliable is its technology and the infrastructure to support it ( Hawkridge, 1979).

\section{Advantages and Disadvantages of E-Learning}

\subsection{Advantages of e-learning technology}

E-learning is beneficial to teacher's education, and to all types of learners. It is affordable, saves time, and produces measurable results. E-learning is more cost effective than traditional learning because less time and money is spent traveling. Since e-learning can be done in any geographic location and there are no travel expenses, this type of learning is much less costly than doing learning at a traditional institute.

Flexibility is a major benefit of e-learning. E-learning has the advantage of taking class anytime anywhere. Education is available when and where it is needed. E-learning can be done at the office, at home, on the road, 24 hours a day, and seven days a week. E-learning also has measurable assessments which can be created so both instructors and students will know what the students have learned, when they've completed courses, and how they have performed (DelVecchio \& Loughney, 2006). Students like e-learning because it accommodates different types of learning styles. Students have the advantage of learning at their own pace. Students can also learn through a variety of activities that apply to many different learning styles learners have (Sanam,2009).

E-learning encourages trainees to peruse through information by using hyperlinks and sites on the worldwide Web. Students are able to find information relevant to their personal situations and interest. E-learning allows students to select learning materials that meet their level of knowledge, interest and what they need to know to perform more effectively in an activity. E-learning is more focused on the learner and it is more interesting for the learner because it is information that they want to learn. E-learning is flexible and can be customized to meet the individual needs of the learners (Ibid).

E-learning helps trainees to develop knowledge of the Internet. This knowledge will help learners throughout their careers. It encourages trainees to take personal responsibility for their own learning. When learners succeed, it builds self-knowledge and self-confidence in them. Learners enjoy having the opportunity to learn at their own pace, on their own time, and have it less costly (Naidu,2000).

\subsection{Disadvantages of e-learning technology}

One disadvantage of e-learning is that learners need to have access to a computer as well as the Internet. They also need to have computer skills with programs such as word processing, Internet browsers, and e-mail. Without these skills and software it is not possible for the student to succeed in e-learning. E-learners need to be very comfortable using a computer. Slow Internet connections or older computers may make accessing e-course and e-lessons difficult. This may cause the learners to get frustrated and give up.

Another disadvantage of e-learning is managing computer files and online learning software. For learners with beginner-level computer skills it can sometimes seem complex to keep their computer files organized. Without good computer organizational skills learners may lose or misplace reports causing them to be late in submitting assignments. Some of the students also may have trouble installing software that is required for the class (DelVecchio \& Loughney,2006).

E-learning also requires just as much time for attending class and completing assignments as any traditional classroom course. This means that students have to be highly motivated and responsible because all the work they do is on their own. Learners with low motivation or bad study habits may fall behind (ibid).

Another disadvantage of e-learning is that students may feel isolated from the instructor. Instructions are not always available to help the learner so learners need to have discipline to work independently without the instructor's assistance. E-learners also need to have good writing and communication skills. When instructors and other learners aren't meeting face-to-face it is possible to misinterpret what was meant (Sanam, 2006). 


\section{Barriers in the Utilization of E-Learning Technology}

The growing interest in using e-learning in the form of e-lesson comes from organizations that have traditionally offered distance education programs in diverse modalities. They were aware of the incorporation of online/offline learning in their range as a logical extension of their distance education activities. E-learning is also become an interest to residential campus-based educational organizations as well (DelVecchio \& Loughney,2006).

Educational institutions see e-learning as a way of improving access to their programs. The growth of e-learning is directly related to the increasing access to information and communications technology, as well it's decreasing cost. The capacity of information and communications technology to support multimedia resource-based learning is also relevant to the growing interest in e-lesson and e-learning (Naidu, 2006).

Contemporarily, a growing numbers of teachers are increasingly using e-learning as a tool of educational technology to support and blend their teaching in teachers training institutions. The current student population (often called the "Net Generation", or "Millennial") and teachers trainees, who have grown up using educational technology also expect to see it being used in their educational experiences (Brown, 2000 in Naidu 2006).

Educational organizations, no exception to teachers training institutions to see advantages in making their programs accessible via a range of distributed locations, including on campus, is not without constraints and limitations. The fundamental obstacle to the growth of e-learning is lack of access to the necessary technological infrastructure, for without it there can be no e-lessons and e-learning. Poor or insufficient technology infrastructure is just as bad, as it can lead to sleazy experiences that can cause more damage than good to teachers, students and the learning experience. While the costs of the hardware and software are falling, often there are other costs that have often not been factored into the deployment of e-learning ventures. The most important of these include the costs of infrastructure support and its maintenance, and appropriate training of staff to enable them to make the most of the technology (Naidu, 2006).

According to Mungania (2003), lack of ICT skills, low educational completion levels, computer literacy, lack of confidence, or a low sense of self-efficacy, prior experience with computers and e-learning, computer ownership, are actually a more critical factor affecting the uptake of e-learning. He found that Self-efficacy is not concerned with skills but measures 'the judgments of what one can do'. 'Highly self-efficacious students are usually quicker to discard faulty strategies and to display more positive attitudes towards a subject. Self-efficacy influences task choice, amount of effort one puts into a task, persistence and perseverance in the face of obstacles, behavior, motivation, performance, attitudes, outcome expectations, success or failure, nature of feedback received, and psycho-social functioning.

Self-efficacy can be fostered by appropriate skills training, and coaching in time management skills early on in the course. Interventions may need to be in place to support or build that sense of self-efficacy, including nurturing feedback, and positive reinforcement, recognition of participants' efforts by managers including awards, certification, or other incentives. Self-efficacy does not necessarily correlate with skills, therefore it is necessary to provide positive experiences in the initial stages of the e-learning process as a platform for the positive sense of self-efficacy that will support problem-solving and independent learning at later stages (Mungania, 2003).

\section{Overcoming the Barriers}

According to Mungania all of the aforementioned barriers, actual and perceived, primary or secondary, can be overcome by e-learning programs that directly address each issue. 'Barrier reduction strategies have to be planned, continuous, and systematic. These should address personal, situational, technological, organizational, instructional, and content strategies. Computer skills training are fundamental. Appropriate induction, and ongoing skills building, will support the positive self-efficacy that appears to be the primary foundation for e-learning (Mungania, 2003).

$\mathrm{He}$ further argues that 'the three pillars that determine the success or failure of e-learning programs are the interconnectedness among persons, behavior, and environment. These are the three major areas that interventions should target.

Personal: program managers must ensure that e-learners have the 'prerequisite knowledge and skills to participate including computer competency through training, and time management skills.

Beliefs and behaviors: e-learners/trainees must have high e-learning self-efficacy and take responsibility for their learning.

Environmental: organizations must support e-learning by offering 'a supportive culture, incentives, models, resources, and fostering e-learning self-efficacy'. These three domains operate in a 'triadic interchange': each needs to be present for a positive e-learning outcome, and neglect of any of the three will undermine success (Mungania, 2003). 
Mungania, emphasizes that organizations need to pay attention to end-user experiences and respond to the specific needs of their employees against her potential inhibitors. Training starting points should be based on identified learner needs, remembering that the initial experience of confidence and self-efficacy is the most crucial platform from which to launch self-confident and self-responsible e-learning. What emerged from both studies is the importance of a carefully planned, staged entry into ICT-based learning, to build self-confidence and motivation amongst new learner (Mungania, 2003).

\section{E-Learning in Teachers Training-Challenges and Lessons}

In today's rapidly changing world, information and communication technologies have become a part of every aspect of society and human's life at an exponential rate. This phenomenon has been of interest to educators, researchers, and policymakers in the field of education. Nowadays, technology integration to enhance student learning and to train students in accordance with timely expectations is one of the most desired missions of educational institutions. To fulfill this, educational institutions have been spending a great deal of money, time and effort on getting the latest technological tools. However, no matter how much technology is brought into classrooms, it does not assure effective integration (Koc and Bakir,, 2010).

Research studies in the adoption of educational technology in the area of pre-service teachers training grouped in to three major categories. The first group has focused on pre-service teacher's trainers and trainees' technology proficiency and experiences. Secondly, a number of studies have examined student teachers' attitudes toward technology use in learning, and their readiness to use educational technology. Lastly, research has dealt with possible barriers influencing pre-service teachers' learning about educational technologies.

Crosby and Speitel (2002, in Naidu, 2006) found that pre-service teacher educators and trainees used computers mostly for their own personal use and large number of them were unaware of the role of educational software and electronic lessons in facilitating, demonstrations, simulations and individual enrichment. Despite increasing number of technologies and level of educational technology provided by teacher education programs, effective and high-level integration of technology into learning and teaching processes is still minority.

One of the commonly mentioned reasons for low level of educational technology utilization could be related to pedagogical beliefs and attitudes towards educational technology. In Ertmer (2005) pointed out that such a beliefs of pre service teachers trainees hold about technology were the ultimate determinant of their decision of whether to use educational technology in teachers training. Teacher's early perceptions and intense experiences with educational technology can form beliefs with cognitive and affective functions. The ways teachers educators use educational technology is usually consistent with their beliefs about teaching and learning. These beliefs become deeply personal and extremely resistant to change overtime and greatly influence teachers' classroom practices (Ertmer, 2005). He observed that pedagogical beliefs still remained as barriers after the removal of access and infrastructure shortcomings.

Numerous studies have focused on impeding factors or barriers to the educational technology preparation of preservice teacher's trainings. Among others, Hew and Brush (2007) summarized common perceived barriers as the lack of access to technology, lack of time and lack of educational technology-supported pedagogical knowledge. Turkmen, Pedersen and McCarty (2007) Investigated Turkish pre-service science teachers' beliefs about their preparation for using educational technology and found that participants were relatively unfamiliar with the advantages of instructional technologies and therefore did not maximize their use.

Other barriers to educational technology implementation in pre-service teachers training that have been shown in the literature include lack of motivation, feelings of discomfort, fear and anxiety about technology (Stone,1998),lack of technological resources, the absence of sufficient technical support, teachers' core values about teaching and learning (Cuban, 2001; Ertmer, 2005), lack of in-service training , lack of time and basic knowledge/skills required for educational technology integration and lack of administrative support (Goktas et al., 2009).

\section{Concluding Remarks}

The revolutionary development and change in the information and communication technology (ICT) in the last fifty years and especially the digital boom in the mid/late 90 s have tremendously changed certain forms of learning and education. E-learning and the recently spreading blended learning is becoming more and more widespread since they differ from the conventional way of teachers education. It has also changed the nature of knowledge, enabling lifelong learning and inspiring individual, autonomous learning as well. It becomes an appropriate method of learning that complements 
traditional learning methods.

To improve e-learning adoption and complementary role, institutional support should not be neglected. Trainees' satisfactions and progress in e-learning depends on institutions providing adequate facilities and infrastructures of technology and support. Teachers training institutions should provide better technology facilities, and human and technical support. It will help trainees' accessed information easily. Moreover, well-designed course content provided students with better learning experiences.

Leadership is important in planning and implementing any e-learning environment. Lack of vision and leadership from the management of the teachers training institutions can greatly affect the ability to successful implementation of an e-learning environment. Moreover, the technological infrastructure of the teachers training institutions is fundamental to the integration of the e-learning environment. For teachers' educators and trainees alike, the ability to gain reliable access to computers and the e-learning environment is a key issue.

To achieve this integration and skill, governments and educators must invest in professional development and curriculum resources as well as in PCs and networks. These two areas of investment reinforce each other and increase the return on either type of investment: professional development and curriculum resources help teachers actually use technology to transform teaching and learning in teachers training institutions, and adequate technology access enables teacher educators to apply what they learn in professional development activities.

Furthermore, a range of methods should be utilized to support the initial and ongoing use of e-learning environments for both teacher educators and trainees. The first method should be through the development of a policy or procedural document that outlines the standard practices for activity on the system. Besides, focusing training on the technological features of the e-learning system and pedagogy are crucial steps to be successful e-learning implementation.

The literature review also shows that implementing the e-learning environment is dependent on the teacher's educator's attitudes toward computers and their access to effective help. In terms of teacher's attitudes toward implementing an e-learning environment, a considerable amount of time and personal interest in using the technology is required. It has also indicated that the importance and need of integrating technology throughout the teacher education curriculum rather than solely teaching technology skills. In general, the review of the literature revealed that the need to have a structural frame work that can be used as a guide for successful implementation of an e-learning environment so as to have technology-enhanced teachers training in Ethiopia, which was dependent on four key factors of ICT infrastructure, ICT leadership, the ICT capacity of the teacher educators and their trainees, and training support initiatives.

\section{References}

Catherall, P. (2005), Delivering e-learning for information service in higher education. Great Britain: Chandos Publishing.

Comerchero, M. (2006), 'What is e-learning?", in E-learning concepts and Techniques (PP.1-12).Pennsylvania, USA: Bloomsburg, University of Pennsylvania.

Cuban, L. (2001), Oversold and Underused: Computer in the class room. Cambridge, MA: Harvard University press. Clark (2000), Big bang or steady revolution? Retrieved April 21, 2006 from http:// www.learning technologies. co.uk/ magazine/article.

Dede, C. (2000), "Emerging technologies and distributed learning in higher Education". In D. Hanna (Ed.), Higher education in an era of digital competition: Choices and challenges. New York: Atwood.

Delvechhio,K. and Loughney, M.(2006), Advantage and disadvantage of e-learning. [Online]. Available: http:// www,bloom.ed/spring 2006-e-book-files/ chapter 4.htm/.

Edelson, D. C., Gordin, D. N., \& Pea, R. D. (1999), "Addressing the challenges of inquiry-based learning through technology and curriculum design". The journal of the Learning Sciences, 8(3\&4),391-450.

Hew, K. \& Brush, T.(2007),"Integrating technology in to K-12 teaching and learning: Current Knowledge gaps and recommendations for future research". Education Technology Research Development, 5(5), 223-252.

Goktas, Y. (2009), Investigation of K-12 Teachers' ICT competencies and the contributing factors in acquiring these competencies. The New Education Review, 17(1) 276-294.

Gomez, L.M, Gordin \& Carlson, P. (1995), "A case study of open-ended scientific inquiry in a technology supported classroom". In J. Greer(Ed.) proceedings of AI-ED 95, Seventh World Conference on Artificial Intelligence in Education(PP.17-24) Charlottes ville, V.A. Association for the advancement of computing in Education.

Hawkridge, D. (1979), "Persuading the London: Routledge Falmer. dons? British Journal of Educational Technology,31(50), 24-33.

Koc, M. \& Baker, N.(2010), "A need assessment survey to investigate pre-service Teachers knowledge, experiences and perceptions about preparation to using educational Technologies". The Turkish Online Journal of Educational Technology 9(4).

Mukhopadhaya, (2002),"Teach for All : a globalizing model of teacher education policy". International Education Journal: Comparative Perspectives.5(4). 
Munganiagania,P. (2003), The Seven E-learning barriers facing Employees: a Research Report Funded by the Masie Centre (New York, 2003).

Pea, R.d. (1994), "Seeing what we build together: Distributed Multimedia learning environments for transformative communications." The Journal of the Learning Sciences, 19(3) 247-298.

Romiszowski, A. (2004), How's the e-learning baby? Factors leading to success or failure of an educational technology innovation", Educational Technology 44(1).

Naidu, S.(2006), E-learning-Guidebook of Principle, procedures and Practices: The University of Melbourne, Melbourne, Victoria . Common Wealth Educational Center for Asia.

Naidu, S. (2000), Designing and Evaluating Instruction for E-learning: University of Melbourne, Australia.

Naidu, S. (1997), Collaborative Reflective practices: instructional design architecture for the internet. Distance Education, 18(2) 257-283.

Sanam. A.(2009), Learner's intention to continue use of e-learning technologies: The case of Iranian Universities. Lulea University of Technology.

Sing, K. (2000), E-learning as an enabler of effective teaching and learning for the knowledge society: University of Terbuka, Malaysia.

Sharma, R. (2003), Barriers in Using Technology for Education in Developing Countries, Computer and Education, Vol.41, No.(1) 49-63.

Spiro,R.J.Feltovich, P.J., Jacobson, M.J., and Coulson, R.L.(1991),"Cognitive Flexibility, constructivism, and hypertext random access instruction for advanced knowledge acquisition in ill-structured domains". Educational Technology, 31(5) 24-33.

Stone, C.A. (1998), "The metaphor of Scaffolding: It's utility for the fields of learning disabilities". Journal of Learning Disabilities, 3(4), 344-364.

Turkmen, H. \& Pedersen, McCarty (2007), "Exploring Turkish Pre-service science Education Teachers understanding of Educational Technology and use". Research in Comparative and International Education, 2(2), 162-171.

Willems (2005), "Flexible learning: Implications of "When-ever". Distance Education, 26(3)429-435. 